\title{
Study on the Adsorption Properties of L-Alanine Modified Chitosan for Cesium Ion in Aqueous Solution
}

\author{
Siman Liu, Shengnan Bin, Jiang Wen, Shi Jiang \\ School of chemistry and chemical engineering. \\ Mianyang Normal University, MNU \\ Mianyang, China \\ e-mail: 2623808586@qq.com
}

\begin{abstract}
The chitosan was modified with L-alanine, which was used for the adsorption of cesium ion in aqueous solution. The results showed that: chitosan modified with $\mathrm{L}$-alanine can remove cesium ions in the solution. When the initial concentration was kept as $150 \mathrm{mg} . \mathrm{L}^{-1}$, the optimal adsorption conditions were: The adsorption time is $100 \mathrm{~min}$, the adsorption capacity was $29.502 \mathrm{mg} / \mathrm{g}$; the adsorption temperature is $25^{\circ} \mathrm{C}$, the adsorption capacity was $30.742 \mathrm{mg} / \mathrm{g}$; dosage of adsorbent was $0.1 \mathrm{~g}$, the adsorption capacity of $61.234 \mathrm{mg} / \mathrm{g}$; $\mathrm{pH}$ was 8, the adsorption capacity of $30.121 \mathrm{mg} / \mathrm{g}$.
\end{abstract}

Keywords-Alanine; Modified; Chitosan; L-alanine; Adsorption; Cesium ion

\section{INTRODUCTION}

The water pollution is now a great challenge for the survival of human beings. Among them, the pollution of metal ions, such as Copper, Lead, Zinc, Chromium, Cadmium, Strontium, and Cesium and so on, causes more and more serious environmental problem [1-5].

Chitosan has been widely used as a kind of biomass adsorbent [6, 7], especially in the adsorption of heavy metal ion [8-11]. Chitosan molecule backbone has the active gene $-\mathrm{NH}_{2}$ and $-\mathrm{OH}$, which can be modified by inserting special groups to Chitosan. Due to the strong activity of $-\mathrm{NH}_{2}$, chitosan moleculars can crosslink with glutaraldehyde, and then react with propylene oxide through nucleophilic addition. This process will insert active chlorine into the chitosan molecules; at last the carboxyl group of L-Alanine molecules could be inserted into chitosan molecules by the activity of chlorine atoms. The final product has carboxyl group, which has better affinity to metal ions and will benefit to the adsorption of $\mathrm{Cs}^{+}$ion in aqueous solution [12].

\section{EXPERIMENT}
A. Materials
Materials used in the experiments are obtained from Chengdu Kelong Reagent Company.

\section{B. Experimental Methods \\ 1) Chitosan modification}

The chitosan was first dissolved into $2 \%$ acetic acid solution, and then sodium hydroxide solution was added slowly with constant stirring, at last a gel-like material formed. The gel like material was washed to neutral using deionized water and then dried at $45^{\circ} \mathrm{C}$. Then $50 \mathrm{~mL}$ of methanol and $50 \%$ glutaraldehyde solution was added to the gel-like material at room temperature with stirring within 4 hours, and reacted for 6 hours at $55^{\circ} \mathrm{C}$ and then filtrated. The filtration was washed with ethanol for 2-3 times. Then epoxy chloropropane, $2 \mathrm{~mol} / \mathrm{L} \mathrm{NaOH}$ solution, $10 \%$ dimethyl sulfoxide solution at $40^{\circ} \mathrm{C}$ were added into the filtration and stirred for 5 hours, stewing for some time and filtrated with Buchner funnel. The precipitation was then washed with deionized water to neutral and then drying at $30^{\circ} \mathrm{C}$ and obtained epichlorohydrin modified chitosan. $2 \mathrm{~mol} / \mathrm{L} \mathrm{NaOH}$ solution added into $2.0 \mathrm{~g}$ L-alanine, and then $1 \mathrm{~mol} / \mathrm{L}$ $\mathrm{pH}=10.5$ phosphate buffer solution was added into this solution together. After the above solution was entirely dissolved, epichlorohydrin modified chitosan was added and react for 24 hours with stirring at $70^{\circ} \mathrm{C}$. Then the reaction solution was washed to neutral with deionized water, drying at $45^{\circ} \mathrm{C}$ and gained the final product L-alanine modified chitosan [13-15].

\section{2) Cesium Ion of Adsorption Experiment}

Add $0.2 \mathrm{~g} \mathrm{~L}$-alanine modified chitosan and $50 \mathrm{~mL}$ $\mathrm{Cs}^{+}$solution into $250 \mathrm{~mL}$ conical flask, and then sealed the flask and placed it on the constant temperature oscillator for planned time to finish the adsorption experiments. Centrifugating the suspension fluid after the adsorption experiment and extracting the clear liquid at upper level for latter experiments. Cesium ion concentration was determined by atomic absorption spectrophotometer. 


\section{RESULTS AND DISCUSSION}

A. Characteristics of Modified Chitosan

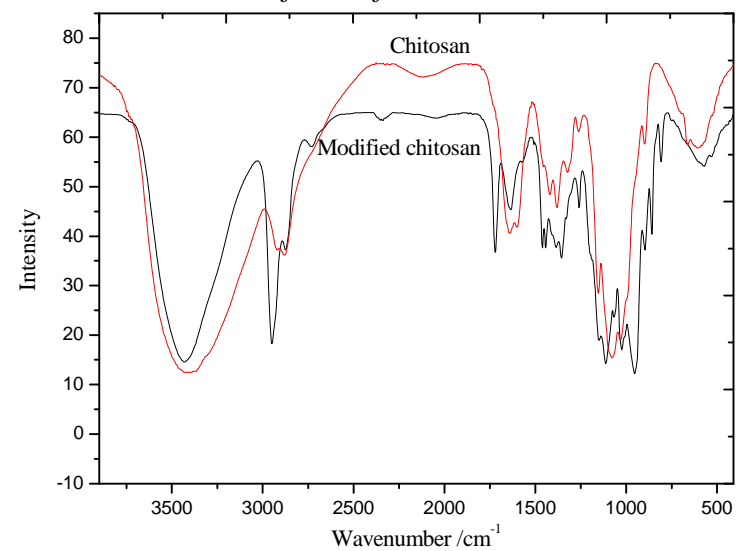

Figure 1 IR spectra of chitosan and modified chitosan

Fig.1 is IR spectra of chitosan and modified chitosan. Absorption band at $3428.81 \mathrm{~cm}^{-1}$ is a combination of the $\mathrm{O}-\mathrm{H}$ stretching and $\mathrm{N}-\mathrm{H}$ stretching vibration. Absorption peaks at $2881.12 \mathrm{~cm}^{-1}$ is attributed to $-\mathrm{C}-\mathrm{H}$ bond stretching vibration; while the strong absorption band at $1641.12 \mathrm{~cm}^{-1}$ and $1602.55 \mathrm{~cm}-1$ are related to the amide CO stretching vibration and $\mathrm{NH}_{2}$ of vibration absorption, respectively. After modification, the absorption band of $\mathrm{NH}, \mathrm{OH}$ (carboxyl and chitosan) stretching vibration remain almost the same as chitosan, so the hybrid absorption peak at $3432.67 \mathrm{~cm}^{-1}$ and an $-\mathrm{C}-\mathrm{H}$ bond stretching vibration peak at $2874 \mathrm{~cm}^{-1}$ still exist. But compared to the infrared spectra of chitosan, the absorption peak at $2950 \mathrm{~cm}^{-1}$ increased apparently, and the absorption peak at $1355 \mathrm{~cm}^{-1}$ which is related with the $-\mathrm{CH}_{3}$ bending vibration peak appeared, indicating that L-alanine modified chitosan microspheres have been effectively prepared. the original strong absorption peaks at $1602.55 \mathrm{~cm}^{-1}\left(-\mathrm{NH}_{2}\right)$ disappeared, indicating that the $-\mathrm{NH}_{2}$ group in chitosan crosslinked with glutaraldehyde successfully. A strong absorption peak at $1720 \mathrm{~cm}^{-1}$ appeared after L-alanine modification means the amino group was added into the chitosan backbone as this absorption band is belong to of $\mathrm{C}=\mathrm{O}$ stretching vibration absorption peak.

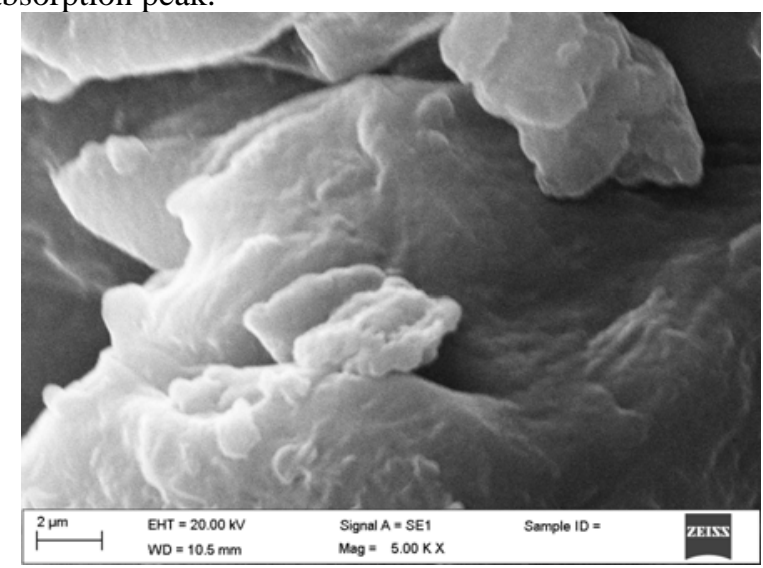

(a) SEM imange of chitosan

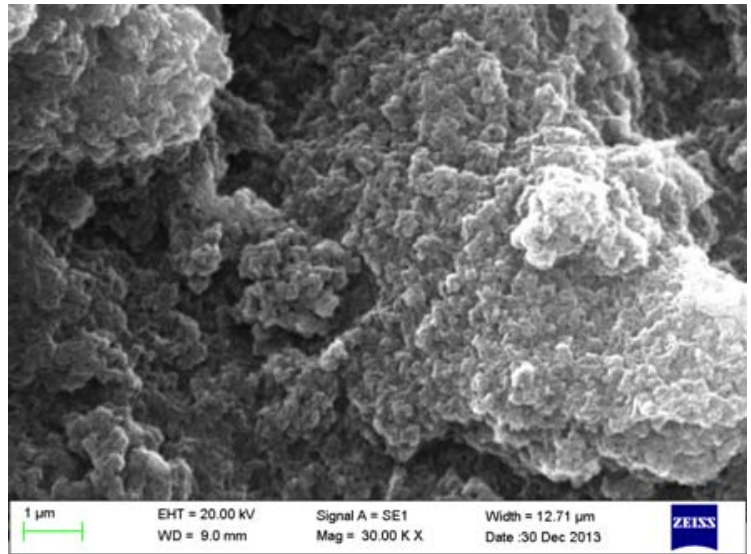

(b) SEM imange of chitosan modified chitosan Figure 2. SEM photograph of Sample

Fig. 2 is the SEM photograph of chitosan and modified chitosan, and it shows that the modified chitosan is more porous than the chitosan. The porous structure of L-alanine modified chitosan means bigger specific surface and is in favor of adsorption of metal ion.

\section{B. Adsorption Properties of Modified Chitosan}

1) Effect of adsorption time on adsorption properties

Fig.3 shows that the modified chitosan has a certain adsorption capacity to $\mathrm{Cs}^{+}$in aqueous solution. When the time lasted from $20 \mathrm{~min}$ to100 $\mathrm{min}$, the curve slope rose and the adsorption amount increased from $28.870 \mathrm{mg} / \mathrm{g}$ to $29.502 \mathrm{mg} / \mathrm{g}$. but when the adsorption time extended to120min, the modified chitosan adsorption capacity of $\mathrm{Cs}^{+}$ion decreased to $29.451 \mathrm{mg} / \mathrm{g}$, The reason for the decrese of adsorption capacity may lies in the saturation of adsorption and desorption. Fig.4 is the adsorption kinetics of modified chitosan to $\mathrm{Cs}^{+}$ion.

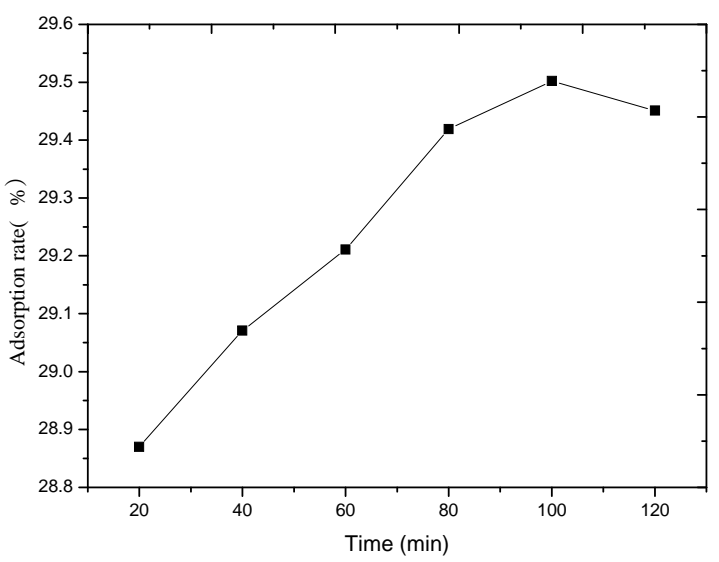

Figure 3. Effect of adsorption time on adsorption properties 


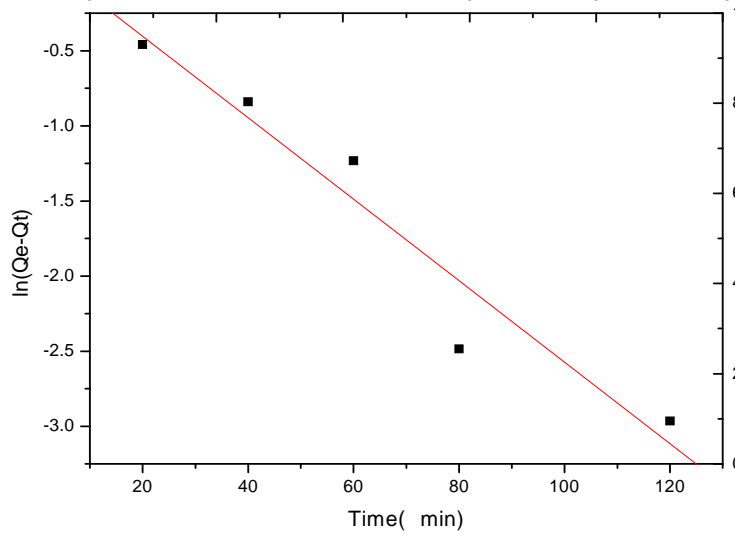

(a) Pseudo first order kinetic fitting curve

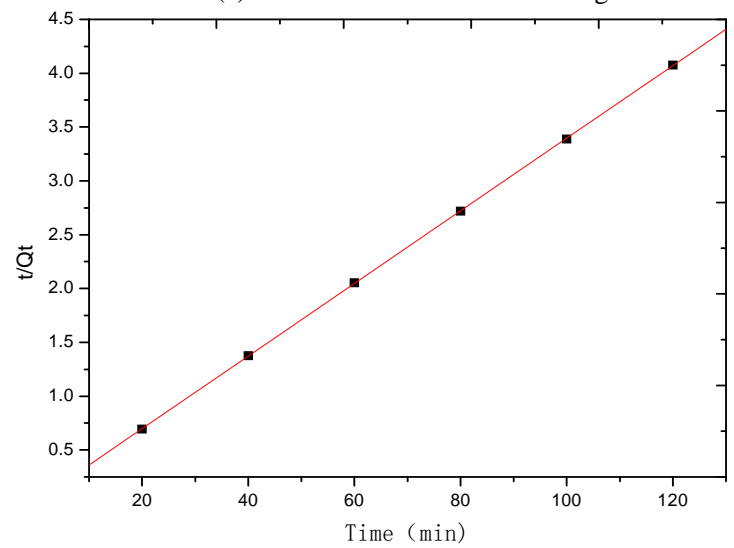

(b) Quasi two order kinetic fitting curve

Figure 4. Adsorption kinetics of modified chitosan

TABLE I. KINETIC FITTING PARAMETERS

\begin{tabular}{|c|c|c|c|}
\hline \multicolumn{4}{|c|}{ Pseudo first order kinetic parameters } \\
\hline$q_{\text {e(exp) }} / m g \cdot g^{-1}$ & $k_{1} / \min ^{-1}$ & $q_{\text {e(cal) }} / \mathbf{m g} \cdot g^{-1}$ & $R^{2}$ \\
\hline 29.502 & 0.02713 & 1.1494 & 0.9338 \\
\hline \multicolumn{4}{|c|}{ Quasi two order kinetic parameters } \\
\hline & $K_{2} / \mathbf{m i n} \cdot m g \cdot g^{-1}$ & $q_{e(c a l)} / m g \cdot g^{-1}$ & $R^{2}$ \\
\hline & 0.04984 & 29.6384 & 0.9999 \\
\hline
\end{tabular}

From Fig.4 and Tab.1, we can see that the test value of adsorption capacity of modified chitosan on $\mathrm{Cs}^{+}$ion is $29.502 \mathrm{mg} / \mathrm{g}$. This value is close to the calculation results of quasi second-order kinetic equation. Moreover, the linear correlation $\mathrm{R}^{2}$ of quasi second order kinetics is higher than that of the pseudo first-order kinetics. So the adsorption process of L-alanine modified chitosan to $\mathrm{Cs}^{+}$ ion should follows the quasi second-order dynamics [16].

\section{2) Effect of adsorption temperature on adsorption properties}

From Fig.5, it can be seen that experimental temperature will affect the adsorption capacity. The adsorption capacity and adsorption rate decreased from $30.742 \mathrm{mg} \cdot \mathrm{g}^{-1}$ at $25^{\circ} \mathrm{C}$ to $28.102 \mathrm{mg} \cdot \mathrm{g}^{-1}$ at $60{ }^{\circ} \mathrm{C}$. But when the temperature rose from $60{ }^{\circ} \mathrm{C}$ to $90{ }^{\circ} \mathrm{C}$, the adsorption capacity only has small change.

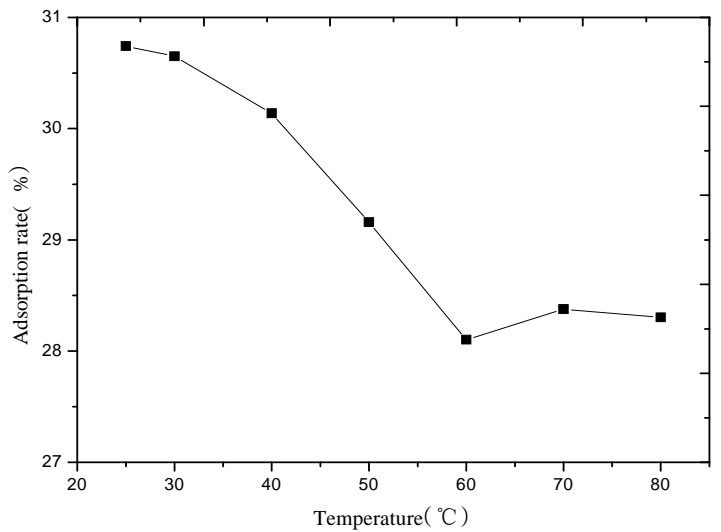

Figure 5. Effect of temperature on adsorption property

\section{3) Effect of $p H$ value on adsorption properties}

From Fig.6, we can see that the $\mathrm{pH}$ value of the solution has a certain effect on the adsorption efficiency. When the $\mathrm{pH}$ value of the solution changed from 4 to 8 , the adsorption capacity increased from $25.475 \mathrm{mg} \cdot \mathrm{g}^{-1}$ to $30.121 \mathrm{mg} \cdot \mathrm{g}^{-1}$. The experimental results showed that the alkaline environment is conducive to the adsorption of $\mathrm{Cs}^{+}$ion for modified chitosan.

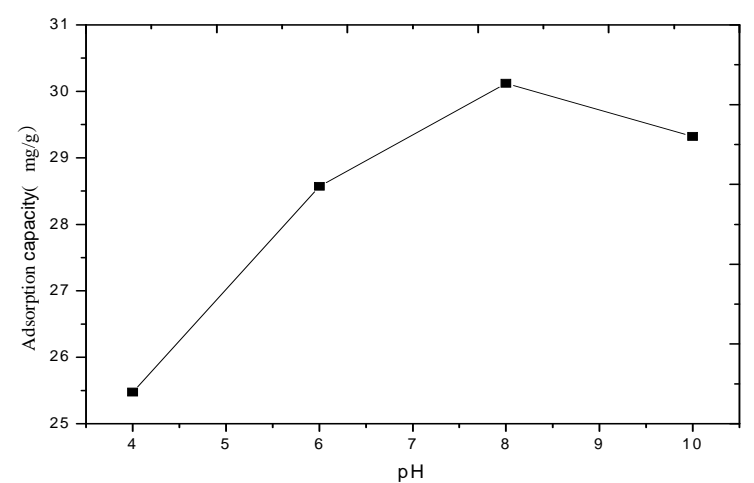

Figure 6. Effect of $\mathrm{pH}$ value on adsorption properties

4) Effect of adsorbent dosage on adsorption properties

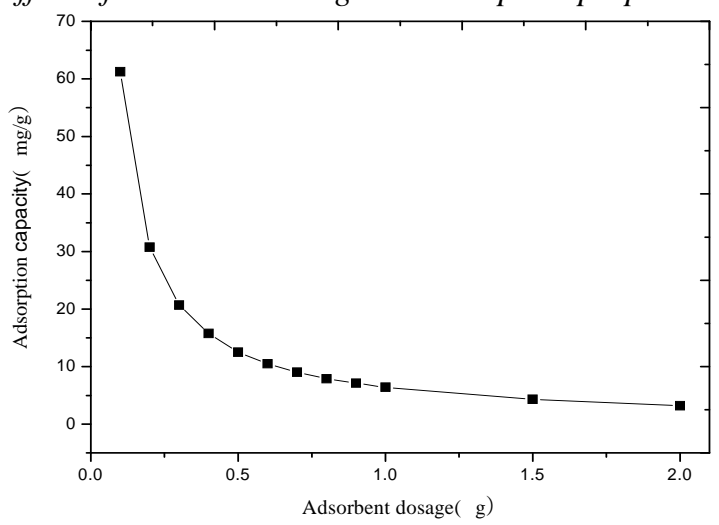

Figure 7. Effect of adsorbent dosage on adsorption properties

Fig.7 shows that the amount of adsorbent has a great influence on the adsorption capacity. The adsorption capacity decreases with the increase of the dosage of the adsorbent. When the dosage of the adsorbent is $0.1 \mathrm{~g}$, the adsorption capacity can reaches to $61.234 \mathrm{mg} \cdot \mathrm{g}^{-1}$, but when the dosage of the adsorbent is $0.6 \mathrm{~g}$, the adsorption 
capacity decreases to $10.495 \mathrm{mg} \cdot \mathrm{g}^{-1}$; and then when the dosage of the adsorbent rises to $2 \mathrm{~g}$, the adsorption capacity only has about $5 \mathrm{mg} \cdot \mathrm{g}^{-1}$.

\section{5) Effect of initial concentration on adsorption properties}

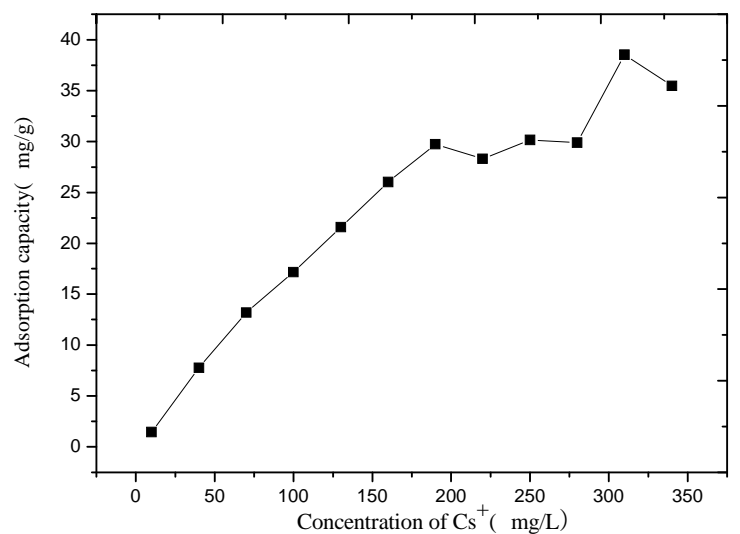

Figure 8. Effect of initial concentration on adsorption properties

From Fig.8, it can be seen that the adsorption capacity increases first and then became mild with the increase of $\mathrm{Cs}^{+}$ion concentration. When the concentration of $\mathrm{Cs}^{+}$ion was $10 \mathrm{mg} \cdot \mathrm{L}^{-1}$, the adsorption capacity was the smallest value of $1.450 \mathrm{mg} \cdot \mathrm{g}^{-1}$. When the ion concentration of $\mathrm{Cs}^{+}$increased from $10 \mathrm{mg} \cdot \mathrm{L}^{-1}$ to 190 $\mathrm{mg} \cdot \mathrm{L}^{-1}$, the adsorption capacity increased rapidly. When the $\mathrm{Cs}^{+}$ion concentration is between $190 \mathrm{mg} \cdot \mathrm{L}^{-1}$ and 280 $\mathrm{mg} \cdot \mathrm{L}^{-1}$, the adsorption curve is flat, and the adsorption capacity slowed down and maintained at a stable level.

The adsorption of solid and liquid system usually complies with Langmuir isothermal adsorption equation [7]. Then isothermal adsorption equation is obtained by Fig.9 as "(1)" and the correlation degree is 0.9812.

$$
\mathrm{Y}=0.02541 \mathrm{X}+0.89449 \quad \mathrm{R}^{2}=0.9812
$$

The correlation degree $\mathrm{R}^{2}$ is close to 1 , indicates that the adsorption process accords with the Langmuir isotherm adsorption equation.

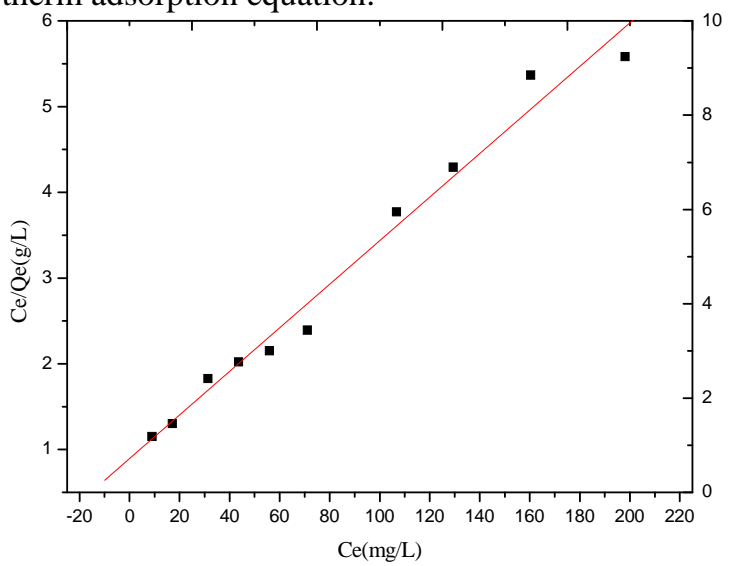

Figure 9. Isothermal adsorption curve fitting

\section{IV.CONCLUSIONS}

The chitosan was modified with L-alanine, which can remove cesium ion in the solution. The results obtained in this paper can provide a reference for the treatment of $\mathrm{Cs}^{+}$ion in radioactive wastewater.

\section{ACKNOWLEDGMENT}

The research was supported by Mianyang Normal University research project (2013A02).

\section{REFERENCES}

[1] Li XiaoYan, Zhang Ye. Research Advances in Treatment Technology of Radioactive Wastewater [J]. Uranium Mining And Metallurgy, 2010, 29 (3): 153-156.

[2] Ge Jianping,Wang Jianyong, Gao Pengjie, Et Al. Study Progress of Treatment Technologies for The Low Level Radicative Liquid Waste [J]. Hebei Huagong, 2013, 36 (3): 64-66.

[3] Yi Facheng Li Yuxiang Tang Rong Shi, Et Al. Astudyon The Adsorptive Capabilities of Mine Ralmaterials for Radionucli De Sr,Cs[J]. China Mining Magazine, 2004, 13 (12): 67-70.

[4] Cai Xuan,Liu Yan, Zhang Yun, Et Al. Progress In Treatment Processes Of Radioactive Wastewater From Nuclear Accident[J]. Chemistry, 2012, 75 (6): 483-488.

[5] Gao Xiaolei, Guo Tan, Zhang Huifang, Et Al. Research Progress in the Adsorption of Strontium Ions [J]. Chinese Mining, 20, 2011 (12): 103-107.

[6] Jiang Tingda. Chitosan[M]. Beijing: Chemical Industry Press, 2001.

[7] Hejazi R, Amiji M. Chitosan-Based Gastrointestinal Delivery Systems [J]. Journal of Controlled Release, 2003, 89(2):151-165.

[8] Chen A H, Liu S C, Chen C Y, Et Al. Comparative Adsorption of $\mathrm{Cu}(\mathrm{Ii}), \mathrm{Zn}(\mathrm{Ii})$, And $\mathrm{Pb}(\mathrm{Ii})$ Ions in Aqueous Solution on the Crosslinked Chitosan with Epichlorohydrin.[J]. Journal of Hazardous Materials, 2008, 154(1-3):184-191.

[9] H.Süheyla Kas. Chitosan: Properties, Preparations and Application to Microparticulate Systems [J]. J Microencapsul, 2009, 14(6):689-711.

[10] Chiou M S, Li H. Adsorption Behavior of Reactive Dye in Aqueous Solution on Chemical Cross-Linked Chitosan Beads [J]. Chemosphere, 2003, 50(8): 1095-1105.

[11] Cheng S S, Yang X H, Zhang C H, Et Al. Adsorption of $\mathrm{Cd}^{2+}$ And $\mathrm{Pb}^{2+}$ by Chitosan[J]. Journal of Fisheries of China, 2011, 35(3):410-416.

[12] Chen Wei, Lin Youwen, Luo Hongbin Et Al. Complexation of Carboxymethyl Chitosan with Calcium Ions[J]. Journal of Fujian Medical University, 34, 2000 (2): 163-165

[13] Qiong Qiong He, Xu Xian Xiao, De Yun Feng. Preparation of Glutamic Acid-Modified Chitosan Nanoparticles and Gene Transfection Research in Vitro[J]. Science \& Technology Review, 2008, 26 (16): 34-37.

[14] Dang Mingyan,Li Junjie,Zhang Xiaolei. Research Progress on Preparation and Application of Modified Chitosan Microspheres [J]. Transactions of Shenyang Ligong University, 2014, 33 (2): $1-5$.

[15] Xue Xue,Zhou XuZhang, Zhang GuiJun. Adsorption of $\mathrm{Cu}^{2+}$ and $\mathrm{Pb}^{2+} \quad$ By Ethylenediamine Modified Chitosan Magnetic Microspheres[J]. Guangzhou Chemical Industry, 2010, 38 (6): 81-84.

[16] Xu Jianping, Zhou Limin, Huang Qunwu, et al. Adsorption Performance of Thiourea Modified Chitosan Microspheres to $\mathrm{Pt}^{4+}$ And $\mathrm{Pd}^{2+} \mathrm{I}$. Adsorption Equilibrium and Kinetics [J]. Petrochemical Technology, 2009, 38 (5): 557-562.

[17] Zhou Limin, Huang Qunwu, Liu Zhirong. Adsorption of $\mathrm{Hg}^{2+}, \mathrm{Cu}^{2+}$ And $\mathrm{Ni}^{2+}$ By Magnetic Chitosan Microspheres Modified Using Thiourea[J]. Chemical Reaction Engineering and Technology, 2008, 24 (6): 556-561. 